\title{
Evaluation of Changes in TMJ Position for Angle Class I Malocclusion After Orthodontic Treatment by Using Cephalometric Radiograph
}

\author{
JianKe Khoo ${ }^{*}$, Thahar Bergman², Laviana Avi², Firman Ria N² \\ ${ }^{1}$ Senior Student in Faculty of Dentistry, Universitas Padjadjaran, Bandung 40132, Indonesia \\ ${ }^{2}$ Lecturers in Faculty of Dentistry, Universitas Padjadjaran, Bandung 40132, Indonesia
}

*E-mail: khoojianke@gmail.com

\begin{abstract}
Objective: A concern in fixed appliances orthodontic treatment besides reestablishing the normal occlusion characteristics might cause repositioning of the condyle position in TMJ region. The objective of this research is to find out whether there is a difference of TMJ position in Angle class I malocclusion type 1,2,3, 4, and 5 before and after fixed appliances orthodontic treatment.

Methods: This research is a pre-and-post design study with analytical statistical approach which compared the TMJ position obtained from tracings 80 lateral cephalometric radiographs before and after fixed appliances orthodontic treatment. Purposive sampling technique was used to determine the sample size in Orthodontic Department of Rumah Sakit Gigi dan Mulut Universitas Padjadjaran from 2009-2015. The data was analyzed by using Kolmogorov-Smirnov Test and paired t-test.

Results: This study revealed that the changes of condyle position in Condylion to Vertical $\mathrm{T}$ line (horizontally) after orthodontic treatment is not significant $(\mathrm{P}>0.05)$ in Angle class I malocclusion. However, the difference of condyle position in Condylion to TC line (vertically) shows a significant difference $(\mathrm{P}<0.05)$ in Angle class I malocclusion.
\end{abstract}

Conclusion: The distance of the condyle from Condylion to TC line increased after fixed appliances orthodontic treatment for Angle class I malocclusion patients.

Keywords: angle class I malocclusion, cephalometric radiograph, fixed appliances orthodontic treatment, TMJ position

\section{Introduction}

Malocclusion is considered a worldwide public health problem. It is defined as a change in teeth position and skeletal growth that might cause functional and esthetic problem. $^{1}$ Malocclusion such cross bite, occlusal interference, crowding, and missing teeth can be considered a contributing factor to the changes of temporomandibular joint position. ${ }^{2}$

According to Dewey modification of angle class I malocclusion, Angle class I malocclusion is divided into five type. For Angle class I type 1, anterior crowding teeth consists of rotated, ectopic or impacted teeth which will cause occlusal interference. ${ }^{3}$ The condyle will not be properly positioned in the glenoid fossa in centric relation if the occlusal relationship is not in harmony. ${ }^{4}$

For Angle class I type 2, protruded maxillary incisors will affect the movement patterns of mandible because the anterior teeth are considered the anterior guidance of mandible movement. During the mandibular movement, the mandibular anterior teeth will occlude with the palatal surface of the maxillary anterior teeth. If the surface is quite steep, mandible will take a steep-incline path during mandibular vertical movement. ${ }^{5}$ This might cause remodeling of condyle in order to adapt to physical changes from functioning teeth and mechanical forces applied on TMJ. ${ }^{6}$

In addition, anterior cross-bite is the term that used to explain an occlusal problem which involves the position of the maxillary anterior teeth being more palatal to the mandibular anterior teeth. In Angle class I type 3 patients, there is a habitual established cross-bite of the anterior teeth, resulting in functional forward shift of the mandible when the mouth is close. ${ }^{7}$ When the mandible shifts anteriorly, the condyle position will not remain in the centric position in glenoid fossa. This will stimulate the changes of condyle position for the adaption of functional loads.

For posterior cross-bite in Angle class I type 4, it is characterized by the buccal cusps of the maxillary teeth occlude lingually against the buccal cusps of the 
corresponding mandibular teeth. ${ }^{8}$ Lateral deviation of the mandible will happen in posterior cross-bite due to the occlusal interference. Some of the authors report that the condyles on the cross-bite side are positioned significantly more superiorly and posteriorly in the glenoid fossa than those on the non-cross bite side. ${ }^{9}$

Furthermore, mesial drift of molars in Angle class I type 5 will also affect the condyle position. Premature loss or early extraction of molars could affect the balance of all occlusion negatively because of the mesialization of the posterior teeth. The imbalanced occlusion may cause mandibular displacement when the mandible occludes in maximum intercuspal position and might lead to remodeling of the condyle Condylar remodeling is a physiologic process that targets to adapt the temporomandibular structure for achieve the functional demands. This process is based on the mechanical forces sustained by the TMJ and the adaptive capacities of the condyle..$^{10,11}$

Cephalometric radiography is a standardized form of skull radiography which can appraise the relationships between the teeth to the jaws and the jaws to the rest of the facial skeleton. ${ }^{12}$ In order to focus the clinical actions during treatment and influence facial growth, lateral cephalometric radiograph perform as an effective diagnostic tool for identifying facial growth patterns or growth direction. ${ }^{13}$ It is useful in recognizing and determining the changes which brought by orthodontic treatment. ${ }^{14}$

When the malocclusion is corrected and functional deviation is eliminated, condyles will take a symmetric and normal position. ${ }^{9}$ Thus; this might lead to the changes in condyle position after orthodontic treatment. There is limited information about the difference of TMJ position before and after orthodontic treatment. Therefore, this study is to investigate the difference of TMJ position after orthodontic treatment in patient who had Angle class I type $1,2,3,4,5$ and determine the effect of fixed appliances orthodontic treatment to the TMJ position by using cephalometric radiograph.

\section{Material and Method}

This study was a pre-post design research analyzed with paired t-test. Since the data of cephalometric radiograph shows that the patient had Angle class I type 1, 2, 3, 4, 5 available on a smaller scale, purposive sampling was used in this research. The data obtained from 80 lateral cephalometric radiographs before and after fixed appliances orthodontic treatment which using multiloop edgewise arch wire (MEAW) technique, from 2009 until 2015 in Clinic PPDGS Orthodontic RSGM UNPAD. The samples consisted of 40 young adult patients from age 1830 years old, with a mean age 20.3 years.

The sample criteria included patient with skeletal class I and Angle class I type 1/ type 2/ type 3/ type 4 or type 5 malocclusion; cephalometric radiograph with clear anatomical landmark and good exposure; patients who treated by using fixed orthodontic appliance with multiloop edgewise arch wire (MEAW) technique within 2-3 years. The exclusion criteria of the sample were distortion of cephalometric radiograph data; the reference line and anatomic landmark on the cephalometric radiograph is not clear or superimposed and patients with TMJ disorders.

Two linear measurements were used for assessing the condyle position in the cranial base. (Figure 1) Manual tracing of cephalometric radiograph on acetate tracing paper was carried out by same operator using a sharp $4 \mathrm{H}$ pencil. First, Condylion (Co), point $\mathrm{T}$ and point $\mathrm{C}$ were marked on the cephalometric radiograph. Next, TC line was drawn by passing through point $\mathrm{T}$ (the most superior point of the anterior wall of the sella turcica at the junction with tuberculum sella) and point $\mathrm{C}$ (the point at the most anterior point of the cribriform plate at the junction with the nasal bone). T Vertical line (VertT) was drawn passing through point $\mathrm{T}$ and at right angles to the $\mathrm{TC}$ line. A line was drawn from Condylion (Co) to $\mathrm{T}$ Vertical line (VertT) and another line was drawn from Condylion (Co) to TC line.15 Furthermore, the distance between Condylion (Co) to T Vertical line (VertT) and the distance between Condylion (Co) to $\mathrm{TC}$ line on cephalometric radiograph was measured by using digital calliper in millimetres (mm). These steps were performed three times on the same cephalometric radiograph with one week interval time to maintain the validity of data.

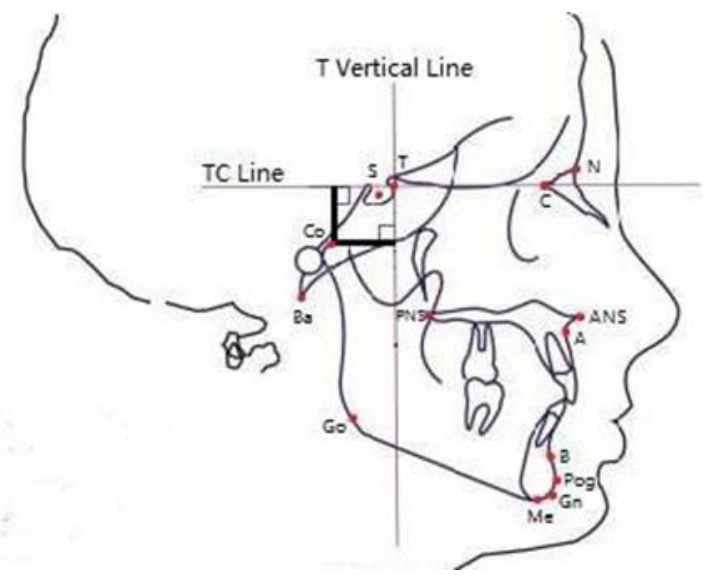

Figure 1. LinearMeasurementof TemporomandibularJoint Position

\section{Results}

Normality test was done to determine if the data collected from the subjects was normally distributed. The normality test used in this research was Kolmogorov-Smirnov Test. When the $(p>0.05)$, we could conclude that the data of the research were normally distributed. Based on table 1, it could be seen that the data of all types of Angle class I malocclusion were normally distributed. Therefore, parametric statistical analysis paired sample t-test could be carried out to analyze the data.

Besides, paired sample t-test was carried out by using SPSS 20.0, with a significant value $(p<0.05)$. The $\mathrm{p}$ 
value of Condylion to Vertical T line $(\mathrm{X})$ in Angle Class I type 1, 2, 3, 4 and 5 were more than 0.05 ( $p=0.494, p=$ $0.841, p=0.802, p=0.426, p=0.278)$, which showed that the differences of Condylion before and after fixed appliances orthodontic treatment in horizontal linear measurement was not significant statistically in any types of Angle Class I malocclusion. Moreover, the $p$ value of Condylion to TC Plane (Y) in Angle Class I Type 1, 2, 3, 4 and 5 were less than $0.05(p=0.000, p=0.000, p=$ $0.004, p=0.011, p=0.000)$. Thus, a statistically association was found between the differences of Condylion in vertical linear measurement in all five types of Angle Class I malocclusion (Table 2).

Table 1. Normality Test Result of Condylion to Vertical T Line (X) and Condylion to TC Plane (Y) in Angle Class I Type 1, 2, 3, 4, 5 Malocclusion

\begin{tabular}{cccccccccc} 
& \multicolumn{3}{c}{ Co-Vert T $(\mathbf{X})$} & \multicolumn{3}{c}{ Co-TC Plane (Y) } \\
\cline { 2 - 9 } Variables & \multicolumn{3}{c}{ Pre } & \multicolumn{2}{c}{ Post } & & Pre & & \multicolumn{2}{c}{ Post } \\
\cline { 2 - 10 } & Sig. & F & Sig. & F & Sig. & F & Sig. & F \\
\hline Type 1 & 0,868 & ND & 0,997 & ND & 0,841 & ND & 0,762 & ND \\
Type 2 & 0,954 & ND & 0,600 & ND & 0,998 & ND & 0,999 & ND \\
\cline { 2 - 10 } Type 3 & 0,556 & ND & 0,898 & ND & 0,811 & ND & 0,966 & ND \\
\cline { 2 - 10 } Type 4 & 0,814 & ND & 0,966 & ND & 0,968 & ND & 0,465 & ND \\
\cline { 2 - 9 } Type 5 & 0,916 & ND & 0,784 & ND & 0,659 & ND & 0,333 & ND \\
\hline
\end{tabular}

Ref: Normal if $\mathrm{p}>0.05$, Co-Vert $\mathrm{T}(\mathrm{X})=$ Condylion to Vertical $\mathrm{T}$ Line, Co-TC Plane $(\mathrm{Y})=$ Condylion to TC Plane $(\mathrm{Y})$, Pre= Pre-treatment, Post $=$ Post-treatment, Sig. $=p$-value, $F=$ Distribution, $N D=$ Normal Distributed

Table 2. Result of Condylion to Vertical T Line (X) and Condylion to TC Plane (Y) in Angle Class I Type 1, 2, 3, 4, 5 Before and After Fixed Appliances Orthodontic Treatment by using Cephalometric Radiograph

\begin{tabular}{|c|c|c|c|c|c|c|}
\hline Variables & & Pre & Post & $\mathrm{n}$ & $d$ & Sig. \\
\hline \multirow{2}{*}{$\begin{array}{l}\text { Angle class } \\
\text { I type } 1\end{array}$} & $\mathrm{X}$ & 18.303 & 18.054 & 35 & -0.249 & 0.494 \\
\hline & $\mathrm{Y}$ & 20.551 & 22.562 & 35 & 2.010 & $0.000 *$ \\
\hline \multirow{2}{*}{$\begin{array}{l}\text { Angle class } \\
\text { I type } 2\end{array}$} & X & 17.811 & 17.917 & 13 & 0.106 & 0.841 \\
\hline & $\mathrm{Y}$ & 19.957 & 22.332 & 13 & 2.375 & $0.000 *$ \\
\hline \multirow{2}{*}{$\begin{array}{c}\text { Angle class } \\
\text { I type } 3\end{array}$} & $X$ & 18.313 & 18.453 & 18 & 0.139 & 0.802 \\
\hline & $\mathrm{Y}$ & 20.843 & 22.775 & 18 & 1.932 & $0.004 *$ \\
\hline \multirow{2}{*}{$\begin{array}{l}\text { Angle class } \\
\text { I type } 4\end{array}$} & $\mathrm{X}$ & 17.502 & 16.898 & 12 & -0.603 & 0.426 \\
\hline & $\mathrm{Y}$ & 20.645 & 22.548 & 12 & 1.903 & $0.011^{*}$ \\
\hline \multirow{2}{*}{$\begin{array}{l}\text { Angle class } \\
\text { I type } 5\end{array}$} & $\mathrm{X}$ & 18.499 & 17.958 & 19 & -0.542 & 0.278 \\
\hline & Y & 20.574 & 22.255 & 19 & 1.682 & $0.000 *$ \\
\hline
\end{tabular}

Ref: Signficant if $\mathrm{p}<0,05, \mathrm{X}=$ Condylion to Vertical $\mathrm{T}$ Line, $\mathrm{Y}=$ Condylion to TC Plane, Pre $=$ Pre-treatment, Post $=$ Post-treatment, $\mathrm{n}=$ Sample Size, $d=$ Differences, Sig. =p-value, $*=$ Significant

\section{Discussion}

A concern in orthodontic treatment with fixed appliances besides reestablishing the normal and balance occlusion characteristics might cause repositioning of the condyle position in the TMJ region. The temporomandibular joint (TMJ) can considered as a one of the most complex joint in human body and it has a strong association with dental occlusion and jaw-to-jaw relationship. The position and function of condyle portion of TMJ normally affected by age, facial growth pattern, pathological functional alterations, decreased or increased muscular activity, occlusal force, and dental occlusion changes. ${ }^{16,17}$

The objective of orthodontic treatment is to reestablish the normal and balance occlusion characteristics. The maxillary arch should match with the mandibular arch to produce a perfect intercuspation and promote maximum function with minimum effort in consideration of the durability of the stomatognathic system. ${ }^{18}$ To determine where the final condylar position should be located after orthodontic treatment may be an important issue because orthodontic treatment can alter the mandibular occlusal position. ${ }^{19}$

The lateral cephalograms in pre-treatment and posttreatment stages were evaluated to see the difference of TMJ position in Angle Class I malocclusion type 1, 2, 3, 4, 5. By using lateral cephalometric radiograph, it allowed orthodontics in assessment of a trend of dental or skeletal growth and to observe the changes during/after the treatment. ${ }^{20}$ Cephalometric radiograph also considered as a common approach in radiographic to evaluate TMJ due to its availability, low radiation requirement, and affordable cost. $^{21}$

In this study, we attempted to determine if there was any difference in TMJ position in Angle class I malocclusion before and after fixed appliances orthodontic treatment. Position changes were evaluated by lateral cephalometric analysis. The study sample was divided into five groups according to the type of Angle class I malocclusion which is type 1 (anterior crowding), type 2 (protrusive maxillary incisors), type 3 (anterior crossbite), type 4 (posterior crossbite) and type 5 (mesialization of permanent molars). ${ }^{22}$

The TMJ position was measured in relation of two reference lines. The ' $\mathrm{X}$ ' axis was referred to vertical $\mathrm{T}$ line and ' $\mathrm{Y}$ ' axis was formed by TC line. TC line, also known as cranial base line was used as a reference line in this study because it remains unchanged after age 5 . Furthermore, Viazis reported that TC line act as a stable cranial reference line which does not change with growth, ${ }^{15} 23$ For vertical $\mathrm{T}$ line, it has been used by Baccetti et al. in their research study about craniofacial changes. ${ }^{15,24}$

There are two linear measurements were used to determine the condyle position in the cranial base which are Condylion (Co) to $\mathrm{TC}$ line and Condylion (Co) to Vertical T line (Vert-T). We compared each measurement from five group of samples before and after orthodontic treatment. The mean values were different in most cases but these differences were not statistically significant in Angle class I malocclusion type 1, 2, 3, 4, 5 when compare condyle position from Condylion to Vertical $\mathrm{T}$ 
line. However, there was a significant difference when compare condyle position from Condylion to TC line in all types of Angle class I malocclusion.

The mean difference in Condylion to Vertical $\mathrm{T}$ line before and after orthodontic treatment is only $-1.4 \%$ in Angle class I type 1, 0.6\% in Angle class I type 2, 0,8\% in Angle class I type 3,-3.4\% in Angle class I type 4 and $2.9 \%$ in Angle class I type 5. The mean values showed that in Angle class I type 1, 4, and 5 the condyle moved slightly forward after orthodontic treatment and condyle position in Angle class I type 2 and type 3 move backward in a very small range. But, statistical analysis did not reveal any significant difference between the condyle position when measure from Condylion to Vertical T line.

This result is similar with the results of Richter et al, and Kinzinger et al's research which showed that the condylar position could remain unchanged after orthodontic treatment. They found the difference of condyle position before and after orthodontic is not significant statistically after neutroclusion was achieved. ${ }^{25,26}$ Moreover, Ackerman and Proffit also stated that the condyles should not be displaced from their retruded position during treatment by more than a small distance. ${ }^{27}$

The not significant result in this study may be occurred because the changes in condylar position are generally very small. Besides, other factors such as age, symptomatic or asymptomatic temporomandibular joint disorder (TMD) samples, skeletal problem, and types of orthodontic treatment also will affect the results in this study. Some of these studies showed a significant relation in changes of condyle position after orthodontic treatment. ${ }^{16,21,28}$

For the mean difference in Condylion to TC line before and after orthodontic treatment, Angle class I type 1 is $9.8 \%$, Angle class I type 2 is $11.9 \%$, Angle class I type 3 is $9.3 \%$, Angle class I type 4 is $9.2 \%$ and for Angle class I type 5 is $8.2 \%$. The p-value of this five groups of sample were less than 0.05 which showed that that was a statistically significant effect observed in the condylar osition for five types of Angle class I malocclusion before and after orthodontic treatment. In this study, we found that at the end of the treatment, the condyle position would be located at a more inferior positon.

The differences in condyle position observed in this presence study could possibly explained by the presence of changes in vertical dimension. Reduction of vertical dimension after orthodontic treatment might cause the mandible move upward and cause the condyle to displace downward. Changes in posterior tooth contact or anterior tooth contact, extraction of premolars, retraction of incisors, will affect the vertical dimension. ${ }^{29,30}$

Furthermore, muscle action will cause different condylar position due to the magnitude of muscle contraction. The condyle position will locate more inferior if the muscular contraction was lighter. ${ }^{31}$ Kecik et al supported that after treatment of malocclusion will change the growth and development of the muscles which will affect its activity. ${ }^{32,33}$ As a response to occlusal fulcrums, the neuromuscular system will displace the condyle more inferiorly to achieve maximal occlusal contact. ${ }^{34}$

The condyle was displaced to a more inferior position within the fossa as a consequence of the adoption of orthodontic treatment. Although the statistic results showed that condyle move downward significantly, this fact may not influence TMJ clinical signs. Dental occlusion had been known as an important factor to cause temporomandibular joint disorder (TMD), but now it become less importance as a contributory factor. ${ }^{35} \mathrm{Up}$ to the present, a lot of scientific research showed that orthodontic treatment did not directly related to temporomandibular joint disorder (TMD). ${ }^{36,37,38}$

Lastly, TMJ position is difficult to measure accurately due to several of reasons. In some cases, linear measurements of condyle position may change in both vertical and horizontal direction whereas some may remain the same. Cone-beam CT (CBCT) has the capability to identify the human craniofacial morphology and the functional interrelationship among the three-dimensional structures. Using CBCT to access the location of condylar will be more accurate as compared to $2 \mathrm{D}$ cephalometric analysis which can be more preferred in the future. ${ }^{39}$

Even though the measurement differences were statistically not significant in Condylion to Vertical T line but the difference was significant in Condylion to TC line, the results showed that the condylar position after orthodontic treatment was slightly different when compared to the position before orthodontic treatment. The distance of the condyle from Condylion to TC line was increase after fixed appliances orthodontic treatment. This study also indicates that the orthodontics should pay more attention to the changes of condyle position before and after orthodontic treatment for a better treatment result.

\section{Conclusions}

In this study, the results show that the differences of condyle position in Condylion to Vertical $\mathrm{T}$ line after orthodontic treatment is not significant for all types of Angle class I malocclusion. However, the differences of condyle position in Condylion to TC line after orthodontic treatment is significant for all types of Angle class I malocclusion. The data concludes that the distance of the condyle from Condylion to TC line was increase after fixed appliances orthodontic treatment.

\section{References}

1. Alves e Luna AC, Godoy F, de Menezes VA. Malocclusion and treatment need in children and adolescents with sickle cell disease. Angle Orthod. 2014;84(3):467-72.

2. Chokalingam S, Felicita DAS. Malocclusion and TMJ disease- A review of literature. IOSR JDMS.2014;13(1): 71-73. 
3. Bernabé E, Flores-Mir C. Dental morphology and crowding: A multivariate approach. Angle Orthod 2006;76(1):20-25.

4. Guttal SS, Nadiger RK, Suvarna A. A Comparison of the Change in Mandibular Condyle/Fossa Relationship with the Use of Anatomic Teeth and Semi-anatomic Teeth in Complete Denture Prosthesis. J Indian Prosthodont Soc. 2013;13(2): 83-88.

5. Okeson JP. Management of temporomandibular disorders and occlusion. St. Louis: Mosby. 2013;95-130 pp.

6. Sreelal T, Janardanan K, Nair AS. Age changes in horizontal condylar angle: A clinical and cephalometric study. J Indian Prosthodont Soc 2013; 13(2):108-112.

7. Ulusoy AT, Bodrumlu EH. Management of anterior dental crossbite with removable appliances. Contemp Clin Dent. 2015;4(2):2013-2016.

8. Andrade S. Characteristics of masticatory muscles in children with unilateral posterior crossbite. Braz Oral Res. 2010;24(2):204-210.

9. Sampaio P, Sekito C, Costa MC, Boasquevisque E, Junior JC. Assessment of condylar growth by skeletal scintigraphy in patients with posterior functional crossbite, Dental PressJ Orthod. 2010;15(5):137-142.

10. Mathew AL, Sholapurkar AA, Pai KM. Condylar Changes and Its Association with Age, TMD, and Dentition Status : A Cross-Sectional Study. Int J Dent. 2011;1-7

11. Halicioglu K, Celikoglu M, Buyuk SK, Sekerci AE, Candirli C. Effects of early unilateral mandibular first molar extraction on condylar and ramal vertical asymmetry. Eur JDent 2014;8(2):178-183

12. Whaites E. Essentials of dental radiography and radiology. Edinburgh: Churchill Livingstone. 2013;161 pp

13. Beatriz M, Araújo BD, Lucato AS. Jarabak's Cephalometric Analysis of Brazilian Black Patients. Braz Dent J 2007;18: 258-262

14. Profitt. Contemporary Orthodontics (4th ed.). Mosby Elsevier Westline Industrial Drive, Missouri. 2007;3-167 pp.

15. Mengi, A, Sharma VP, Tandon P, Agarwal A. The glenoid fossa location in cranial base: in various skeletal malocclusion. J dent her 2015;(2)2:6-10

16. Arieta-miranda, JM, Silva-valencia M, Flores-mir C, Paredes-sampen NA, Arriola-guillen LE. Spatial analysis of condyle position according to sagittal skeletal relationship, assessed by cone beam computed tomography. Prog Orthod 2013;14(36):1-9.

17. Merigue LF, Conti AC, Oltramari-Navarro PV, Navarro RL, Almeda MR. Tomographic evaluation of the temporomandibular joint in malocclusion subjects: condylar morphology and position. Braz Oral Res 2016;30:1-7

18. Cabrera MC, Alberto C, Cabrera G, Freitas SD, Freitas MR. Cephalometric effects of the use of 10-hour Force Theory for Class II treatment. Dental Press J Orthod 2012;17(6):31-40.

19. Tsurata $A$ et al. The relationship between morphological changes of the condyle and condylar posiition in the glenoid fossa. J Orofac Pain 2004;18(2):148-155

20. Issacson KG, Thom A. Guidelines for the use of radiographs in clinical orthodontics. British Orthodontic Society, London; 2001.

21. Yildirim E, Karacay S, Erkan M. Condylar response to functional therapy with Twin-Block as shown by conebeam computed tomography. Angle Orthod 2014;84(6):1018-1025
22. Trehan M, Chugh VK, Sharma S. Prevalence of malocclusion in Jaipur, India. J Clin Pediatr Dent 2009;2(4), 23-25.

23. Viazis AD. The cranial base triangle. J Clin Orthod 1991;25(9):565-570

24. Baccetti, Tollaro, Franchi. Craniofacial changes induced by early functional treatment of Class III malocclusion. Am JOrthod 1996;12:310-318

25. Richter U, Richter F. An MRI-monitored investigation of the condyle-fossa relationship during Herbst appliance treatment. J Orthod 2004;1: 43-51

26. Kinzinger GSM, Roth A, Gulden N, Bucker A, Diedrich PR. Effects of orthodontic treatment with fixed functional orthopaedic appliances on the condyle-fossa relationship in the temporomandibular joint: a magnetic resonance imaging study (Part I) Dentomaxillofac Radiol 2006;35:339-346.

27. Ackerman J, Proffit W. Soft tissue limitations in orthodontics: Treatment planning guidelines. Angle Orthod 1997; 7:327-336

28. Chavan SJ, Bhad WA, Doshi UH. Comparison of temporomandibular joint changes in Twin Block and Bionator appliance therapy: a magnetic resonance imaging study. Prog Orthod. 2014;15(57): 1-7

29. Oshagh M, Karamifar AA, Salehi P, Naseri MM. A comparative study of vertical lip changes after standard edgewise and preadjusted orthodontic treatments. J CranioMax Dis 2012;1(2):68-73

30. Sukhia HR. Lower facial height treatment changes in bimaxillary protrusion orthodontic cases. Pak Oral Dental J 2013;33(1):65-70

31. Piehslinger E, Celar A, Celar R, Jager W, Slavicek R. Reproducibility of the condyle reference position. J OrofacPain 2003;7(1):68-75

32. Kecik D, Koadereli I, Saatci I. Evaluation of the treatment changes of functional posterior crossbite in the mixed dentition. Am J Orthod Dentofacial Orthop 2007;131:202215

33. Thilander B, Rubio G, Pena L, Mayorga CD. Prevalence of Temporomandibular Dysfunction and Its Association with Malocclusion in Children and Adolescents: An Epidemiologic Study Related to Specified Stages of Dental Development. Angle Orthod 2002;72:146-154.

34. Ponces MJ, Tavares JP, Lopes JD, Ferreira AP. Comparison of condylar displacement between three biotypological facial groups by using mounted models and a mandibular position indicator. Korean J Orthod 2014;44(6):312-319

35. Barrera-Mora JM., et al. The relationship between malocclusion, benign joint hypermoility syndrome, condylar position and TMD symptoms. J CraniomandibularPract 2012;30(2):121-130

36. Kinzinger G, Kober C, Diedrich P. Topography and morphology of the mandibular condyle during fixed functional orthopedic treatment: a magnetic resonance imaging study. J Orofac Orthop 2007;68(2):124-147

37. Arici S, Akan H, Yakubov K, Arici N. Effects of fixed functional appliance treatment on the temporomandibular joint. Am J Orthod Dentofacial Orthop 2008;33(6):809-814

38. Machado E, Grehs RA, Cunali PA. Imaging from temporomandibular joint during orthodontic treatment: a systemic review. Dental Press J Orthod 2011;16(3):1-7

39. Wang MF, Otsuka T, Akimoto S, Sato S. Vertical face height and its correlation with facial width and depth in three dimensional cone beam computed tomography evaluation based on dry skulls. J Stomat Occ Med 2013;13(6):120-129 